\title{
Application of Grey Theory to the Field of Economic Forecasting Huang $\mathrm{CY}^{1}$, Lu CY${ }^{1}$ and $\mathrm{Chen}_{\mathrm{Cl}^{2 *}}$ \\ ${ }^{1}$ Department of Nursing, I-Shou University,No. 8, Yida Rd, Yanchao district, Kaohsiung, Taiwan 82445 \\ ${ }^{2}$ Department of Industrial Management, I-Shou University, No. 1, Section 1, Syuecheng Rd., Dashu district, Kaohsiung, Taiwan 84041
}

\begin{abstract}
The Grey model is characterized by basic mathematics and a need for few raw data, but it also lacks the flexibility to adjust the model to increase the precision for the forecasting model. This article shows two types of grey forecasting models, $\mathrm{GM}(1,1)$ and NGBM. The $\mathrm{GM}(1,1)$ shows its fitting ability to the linear raw data and NGBM is superior in fitting nonlinear raw data. In this article, two practical cases are shown to demonstrate the calculation procedures of both models. The results show they are feasible in forecasting.
\end{abstract}

Keywords: GM(1,1); Nonlinear grey Bernoulli model; Number of nurses, Economic growth rate

\section{Introduction}

Grey theory was proposed by Prof. Deng [1] for more than 30 years. It has been successfully applied in many academic fields, such as electrical engineering, education, mechanical engineering, agriculture, high-tech sectors and so on [2-8]. Grey theory is famous for easy calculation and satisfactory result. Comparing to other methods, grey theory need only as few as four data could be modeled to forecast. There is no normality test needed beforehand and there is no level of significance test afterward. This is because that it is impossible to find any regularity based only on these four raw data. The criteria for testing the availability of modelling is relative percentage error (RPE) and average relative percentage error (ARPE) which are most commonly adopted. Therefore, the grey theory is suitable for short term forecasting or temporary reference for making decision or strategy when only limited data in hands.

Due to the need of forecasting precision, there are many improved or hybrid grey models proposed recently [9] used wavelet transform and grey model improved by PSO algorithm to forecast short term electric load [10] used Grey-Markov prediction method to enhance the electric arc furnace reactive power compensation. Sun [11] used the Hybrid Approach by Integrating Brain Storm Optimization Algorithm with Grey Neural Network for Stock Index Forecasting [12] adopted nonlinear grey prediction model with convolution integral $\operatorname{NGMC}(1, \mathrm{n})$ and its application to the forecasting of china's industrial SO2 emissions [13] used an optimized Nash nonlinear grey Bernoulli model based on particle swarm optimization and its application in prediction for the incidence of Hepatitis B in Xinjiang, China [14] predicted water consumption in hospitals based on a modified grey GM $(0,1 \mid \sin )$ model of oscillation sequence: the example of Wuhan city. Viewing the advancement of grey theory, it has been widely applied and accepted. Based on above reasons, the authors would like to introduce the grey theory to reader of Journal of Global Economics and the field of economic forecasting. In this article, the basic $\operatorname{GM}(1,1)$ and NGBM models are introduced for reader's reference.

\section{Mathematical Methodology}

The grey forecasting model is based on the formulation of differential equation. The solution of differential equation is the form of exponential function which could fit observed data with more flexibility. Unlike linear regression, the $\operatorname{GM}(1,1)$ and NGBM could provide better forecasting precision.

\section{Traditional grey model GM $(1,1)$}

This section provides the derivation of traditional grey forecasting in detail.

Step 1: Assume that the original series of data with $m$ entries is:

$\mathrm{X}^{(0)}=\left\{x^{(0)}(1), x^{(0)}(2), \ldots, x^{(0)}(k), \ldots ., x^{(0)}(m)\right\}$,

Where raw matrix $\mathrm{X}^{(0)}$ stands for the non -negative original historical time series data.

Step 2: Construct $\mathrm{X}^{(1)}$ by one time accumulated generating operation (1-AGO), Which is

$$
\mathrm{X}^{(1)}=\left\{x^{(1)}(1), x^{(1)}(2), \ldots, x^{(1)}(k), \ldots ., x^{(1)}(m)\right\},
$$

where

$$
x^{(1)}(k)=\sum_{i=1}^{k} x^{(0)}(i), \mathrm{k}=1,2, \ldots \ldots, \mathrm{m}
$$

Step 3: The result of 1-AGO is monotonic increase sequence which is similar to the solution curve of first order linear ordinary differential equation. Therefore, the solution curve of following differential equation represents the approximation of 1-AGO data.

$$
\frac{d \stackrel{{ }^{(1)}}{d}}{d t}+a \stackrel{\wedge^{(1)}}{X}=b,
$$

where $\wedge$ represents Grey forecast value. The $a$ and $b$ are model parameters and $a$ could not equal to zero[15]. $x(1) \stackrel{\wedge_{X}^{(1)}}{X}(1)=X^{(0)}(1)$ is the corresponding initial condition.

Step 4: The model parameters $a$ and $b$ can be determined by discrete form of Eq. (4)

${ }^{*}$ Corresponding author: Chen $\mathrm{Cl}$, Department of Industrial Management, I-Shou University, No. 1, Section 1, Syuecheng Rd., Dashu district, Kaohsiung, Taiwan 84041, Tel: +886-7-6577711 ext. 5522; E-mail: EddyChen@isu.edu.tw

Received October 24, 2014; Accepted November 10, 2014; Published December 15,2014

Citation: Huang CY, Lu CY, Chen Cl (2014) Application of Grey Theory to the Field of Economic Forecasting. J Glob Econ 3: 131. doi:10.4172/2375-4389.1000131

Copyright: ( $) 2014$ Huang CY, et al. This is an open-access article distributed under the terms of the Creative Commons Attribution License, which permits unrestricted use, distribution, and reproduction in any medium, provided the original author and source are credited. 


$$
\frac{d \hat{X}^{(1)}}{d t}=\lim _{\Delta t \rightarrow 0} \frac{\hat{X}^{(1)}(t+\Delta t)-\hat{X}^{(1)}(t)}{\Delta t} .
$$

If the sampling time interval is unit, then let $\Delta t \rightarrow 1$

$$
\frac{d \hat{X}^{(1)}}{d t} \cong x^{(1)}(k+1)-x^{(1)}(k)=x^{(0)}(k+1), k=1,2,3
$$

and $\hat{X}^{(1)}(\mathrm{t})$ is defined as

$$
\hat{X}^{(1)}(t) \cong p x^{(1)}(k)+(1-P) x^{(x)}(k+1), \mathrm{k}=1,2,3,
$$

where $z^{(1)}$ is termed background value, $P$ is traditionally set to 0.5 . The source model then can be obtained as

$$
X^{(0)}(k)+a z^{1}(k)=b, \mathrm{k}=2,3,4
$$
$\mathrm{b}$ are

From Eq. (8), by least square method the model parameters a and

$$
\left[\begin{array}{l}
a \\
b
\end{array}\right]=\left(B^{T} B\right)^{-1} B^{T} Y_{N}
$$

Where $\mathrm{B}$ and $\mathrm{Y}_{\mathrm{N} \text { are }}$ defined as follows

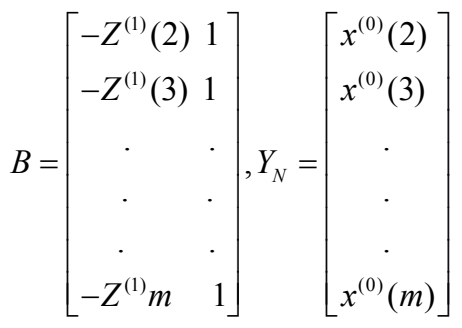

or, $\mathrm{a}$ and $\mathrm{b}$ can be expressed in the following form

$$
\begin{gathered}
a=\frac{\sum_{k=2}^{m}\left[z^{(1)}(\mathrm{k})\right] \sum_{k=2}^{m} x^{(0)}(\mathrm{k})-(\mathrm{m}-1) \sum_{k=2}^{m} x^{(0)}(\mathrm{k}) \mathrm{z}^{(1)}(\mathrm{k})}{(\mathrm{m}-1) \sum_{k=2}^{m}\left[\mathrm{z}^{(1)}(\mathrm{k})\right]^{2}-\left(\sum_{k=2}^{m} z^{(1)}(\mathrm{k})\right)^{2}} \\
b=\frac{\sum_{k=2}^{m} x^{(0)}(\mathrm{k}) \sum_{k=2}^{m}\left[z^{(1)}(\mathrm{k})\right]^{2}-\sum_{k=2}^{m} x^{(0)}(\mathrm{k}) \mathrm{z}^{(1)}(\mathrm{k}) \sum_{k=2}^{m} z^{(1)}(\mathrm{k})}{(\mathrm{m}-1) \sum_{k=2}^{m}\left[\mathrm{z}^{(1)}(\mathrm{k})\right]^{2}-\left(\sum_{k=2}^{m} z^{(1)}(\mathrm{k})\right)^{2}}
\end{gathered}
$$

Step 5: Splve the Eq.(4) together with initial condition, and the particular solution is

$$
\hat{X}^{(1)}(\mathrm{K}+1)=\left(\mathrm{x}^{(0)}(1)-\frac{b}{a}\right) e^{-a k}+\frac{b}{a}, \mathrm{k}=1,2,3 \ldots \ldots \ldots
$$

Hence, the desired forecasting output at $\mathrm{k}$ step can be estimate by inverse accumulated generating operation(IAGO) which is defined as

$$
\hat{X}^{(0)}(\mathrm{K}+1)=\left(1-\mathrm{e}^{-a}\right)\left(\mathrm{x}^{(0)}(1)-\frac{b}{a}\right) e^{-a k}, \mathrm{k}=1,2,3 \ldots \ldots \ldots \ldots
$$

\section{Nonlinear Grey Bernoulli model}

The procedures for deducing NGBM are as follow [16]. The step 1 and 2 are as same as traditional grey model.
Step 3: Equation (4) is a linear differential equation and the only adjustable variable is $P$ [17]. Based on the differential equation theory, Bernoulli equation is introduced to replace the traditional grey differential equation. The Bernoulli equation has the following form

$$
\frac{d \stackrel{\wedge^{(1)}}{X}}{d t}+a \stackrel{\hat{\aleph}^{(1)}}{X}=b\left[\stackrel{\wedge}{X}^{(1)}\right]^{n},
$$

where $n$ belongs to real number. Observing the above equation, when $n=0$, the solution reduces to traditional $\operatorname{GM}(1,1)$, when $n=2$, the solution reduces to Grey-Verhulst equation [18].

Step 4: Discrete form of Eq. (15)

$$
x^{(0)}(\mathrm{k})+\mathrm{az}{ }^{(1)}(\mathrm{k})=\mathrm{b}\left[\mathrm{z}^{(1)}(\mathrm{k})\right]^{n}, \mathrm{k}=2,3,4
$$

where NGBM parameters $a$ and $b$ are calculated by the following matrix manipulation,

$$
\left[\begin{array}{l}
a \\
b
\end{array}\right]=\left(\mathrm{B}^{T} \mathrm{~B}\right)^{-1} B^{T} Y_{N}
$$

The parameters $a$ and $b$ are shown below

$$
\begin{gathered}
a=\frac{\sum_{k=2}^{m}\left[z^{(1)}(\mathrm{k})\right]^{n+1} \sum_{k=2}^{m}\left\{x^{(0)}(\mathrm{k})\left[z^{(\mathrm{l})}(\mathrm{k})\right]^{n}\right\}-\sum_{k=2}^{m}\left[z^{(\mathrm{l})}(\mathrm{k})\right]^{2 n} \sum_{k=2}^{m} x^{(0)}(\mathrm{k}) \mathrm{z}^{(\mathrm{l})}(\mathrm{k})}{\sum_{k=2}^{m}\left[z^{(1)}(\mathrm{k})\right]^{2 n} \sum_{k=2}^{m}\left[z^{(1)}(\mathrm{k})\right]^{2}-\left(\sum_{k=2}^{m}\left[z^{(1)}(\mathrm{k})\right]^{n+1}\right)^{2}} \\
b=\frac{\sum_{k=2}^{m}\left\{x^{(0)}(\mathrm{k})\left[z^{(1)}(\mathrm{k})\right]^{n}\right\}^{n+1} \sum_{k=2}^{m}\left[z^{(1)}(\mathrm{k})\right]^{2}-\sum_{k=2}^{m}\left\{x^{(0)}(\mathrm{k}) z^{(1)}(\mathrm{k})\right\} \sum_{k=2}^{m}\left[z^{(1)}(\mathrm{k})\right]^{n+1}}{\sum_{k=2}^{m}\left[z^{(1)}(\mathrm{k})\right]^{2 n} \sum_{k=2}^{m}\left[z^{(1)}(\mathrm{k})\right]^{2}-\left(\sum_{k=2}^{m}\left[z^{(1)}(\mathrm{k})\right]^{n+1}\right)^{2}}
\end{gathered}
$$

Step 5: The Corresponding particular solution of Eq.(16) together with initial condition

$$
\hat{x}^{(1)}(1)=x^{(0)}(1) \text { is } \hat{X}(\mathrm{~K}+1)=\left[\left(x^{(0)}(1)^{(1-\mathrm{n})}-\frac{b}{a}\right) e^{-a(1-\mathrm{n}) \mathrm{k}}+\frac{b}{a}\right]^{1 /(1-\mathrm{n})}
$$

\section{Error analysis}

Error analysis is needed for examining the precision of forecasted results. Relative percentage error (RPE) compares the real and forecast values to evaluate the precision at specific time $k$. RPE is defined as

$$
R P E=\varepsilon(\mathrm{k})=\frac{x^{(0)}(\mathrm{k})-x(\mathrm{k})}{x^{(0)}(\mathrm{k})} \times 100 \%
$$

where $x^{(0)}(k)$ is the actual value and $\hat{X}^{(0)}(k)$ is the forecasted value by Eq. (20). The total model precision can be defined by average relative percentage error (ARPE) as follows

$$
A R P E=\varepsilon(\operatorname{avg})=\frac{1}{m-1} \sum_{k=2}^{m} \varepsilon(\mathrm{k}), \mathrm{k}=2,3,4, \ldots \ldots \mathrm{m} .
$$

\section{Forecasting by $\mathrm{GM}(1,1)$ and NGBM}

In this section, two practical cases are calculated to demonstrate how grey theory is applied. Normally, $\operatorname{GM}(1,1)$ is a linear model which is suitable for slow changing raw data. NGBM is nonlinear model which is applicable to drastically change raw data. In the Table 1 , according to the statistic data of Ministry of Health and Welfare of Taiwan, the number of nurses grows steadily year by year. Examining the raw data, it shows linear characteristics as the increment is small. Modelling the data from year 2009 to 2012, the point errors are all greatly less than $1 \%$. The average relative percentage error is only $0.074 \%$. The modelling 
Citation: Huang CY, Lu CY, Chen Cl (2014) Application of Grey Theory to the Field of Economic Forecasting. J Glob Econ 3: 131. doi:10.4172/23754389.1000131

\begin{tabular}{|l|c|c|c|c|c|c|}
\hline Year & $\mathbf{2 0 0 9}$ & $\mathbf{2 0 1 0}$ & $\mathbf{2 0 1 1}$ & $\mathbf{2 0 1 2}$ & $\mathbf{2 0 1 3}$ & \\
\hline raw data & 87,361 & 91,724 & 95,529 & 99,801 & 103,277 & \\
\hline predicted data & 87,361 & 91,659 & 95,613 & 99,737 & 104,040 & $a=-0.042$ \\
\hline point error & $0 \%$ & $0.037 \%$ & $-0.007 \%$ & $0.012 \%$ & $0.738 \%$ & $b=86046.9$ \\
\hline average error & & $0.074 \%$ & & & \\
\hline
\end{tabular}

Table 1: Number of nurses in Taiwan from 2009 to 2013

\begin{tabular}{|l|l|l|l|l|l|l|}
\hline Model & year & $\mathbf{2 0 1 0}$ & $\mathbf{2 0 1 1}$ & $\mathbf{2 0 1 2}$ & $\mathbf{2 0 1 3}$ & \\
\hline & raw data & $10.760 \%$ & $4.190 \%$ & $1.480 \%$ & $2.090 \%$ & \\
\hline & $\begin{array}{l}\text { predicted } \\
\text { data }\end{array}$ & $10.760 \%$ & $3.838 \%$ & $2.327 \%$ & $1.411 \%$ & $a=0.543$, \\
\hline GM $(1,1)$ & $\begin{array}{l}\text { point error } \\
\text { average error }\end{array}$ & $0 \%$ & $8.39 \%$ & $-57.243 \%$ & $32.488 \%$ & $b=10.26$ \\
\hline & $\begin{array}{l}\text { predicted } \\
\text { data }\end{array}$ & $10.76 \%$ & $3.893 \%$ & $1.696 \%$ & $1.866 \%$ & $a=-0.108$ \\
\hline NGBM & point error & $0 \%$ & $7.081 \%$ & $-14.604 \%$ & $10.721 \%$ & $b=1.633^{*} 10^{31}$ \\
\hline & average error & & $10.802 \%$ & & & $n=-27.72$ \\
\hline
\end{tabular}

Table 2: Economic Growth Rate of Taiwan from 2010 to 2013

precision is more than $99.9 \%$. The data of year 2013 is served as the criteria for checking the forecasting precision. The forecasted value is 104,040 which is close to the real data 103,277.

Source: Statistic data of Ministry of Health and Welfare of Taiwan

As the previous case is linear, the forecasting result is satisfactory. If the nonlinear case is encountered, the forecasted result will be unacceptable if $\operatorname{GM}(1,1)$ is applied. The case 2 is forecasting of Taiwan economic growth rate from year 2010 to 2013. From Table 2, the modelling error of $\operatorname{GM}(1,1)$ is $32.71 \%$ which is high. This is because there is a drastic drop from year 2010 to 2011 , which is from $10.76 \%$ to $4.19 \%$. The linear $\operatorname{GM}(1,1)$ obviously fails in this case. By applying nonlinear grey forecasting, NGBM, the modelling error is greatly reduced from $32.71 \%$ to $10.8 \%$ which demonstrates the power of nonlinear model.

\section{Conclusions}

The grey theory is easy in its mathematics and the forecasting result is satisfactory. Classified by raw data distribution, $\operatorname{GM}(1,1)$ is suitable for linear data and NGBM is suitable for nonlinear data. The derivation and calculation procedure are shown in this article. Also, two practical cases are demonstrated to show how GM $(1,1)$ and NGBM are adopted to model the raw data. The results show that NGBM is superior than $\mathrm{GM}(1,1)$ if nonlinear data pattern is considered.

\section{Acknowledgement}

The authors would like to thank for financial support from Ministry of Science and Technology under the contract NO. NSC 101-2221-E-214 -020 and I-Shou University under the contract NO. ISU 103-03-03A.

\section{References}

1. Deng JL (1982) Control problems of grey systems. Systems \& Control Letters 1: $288-294$.

2. Samvedi A, Jain V (2013) A grey approach for forecasting in a supply chain during intermittent disruptions. Engineering Applications of Artificial Intelligence 26: 1044-1051.
3. Li GD, Masuda S, Nagai M (2013) The prediction model for electrical power system using an improved hybrid optimization model. International Journal of Electrical Power and Energy Systems 44: 981-987.

4. Chang TS, Ku CY, Fu HP (2013) Grey theory analysis of online population and online game industry revenue in Taiwan. Technological Forecasting and Social Change 80: 175-185

5. Zhao Z, Jianzhou W, Jing Z, Zhongyue Su (2012) Using a Grey model optimized by Differential Evolution algorithm to forecast the per capita annual net income of rural households in China. Omega-International Journal of Management Science 40: 525-532.

6. Wu F, Lin CJ, Wang YT (2012) A Grey Prediction for Optimization Technique in Mobile Computing. Applied Mathematics \& Information Sciences 6: 521S-529S.

7. Tang HWV, Yin MS (2012) Forecasting performance of grey prediction fo education expenditure and school enrollment. Economics of Education Review 31: 452-462.

8. Xu HF, Liu B, Fang ZG (2014) New grey prediction model and its application in forecasting land subsidence in coal mine. Natural Hazards 71: 1181-1194.

9. Bahrami S, Hooshmand RA, Parastegari M (2014) Short term electric load forecasting by wavelet transform and grey model improved by PSO (particle swarm optimization) algorithm. Energy 72: 434-442.

10. Samet H, Mojallal A (2014) Enhancement of electric arc furnace reactive power compensation using Grey-Markov prediction method. let Generation Transmission and Distribution 8: 1626-1636.

11. Sun YQ (2014) A Hybrid Approach by Integrating Brain Storm Optimization Algorithm with Grey Neural Network for Stock Index Forecasting. Abstract and Applied Analysis.

12. Wang ZX (2014) Nonlinear Grey Prediction Model with Convolution Integra $\operatorname{NGMC}(1, n)$ and Its Application to the Forecasting of China's Industrial SO2 Emissions. Journal of Applied Mathematics.

13. Zhang LP, Zheng $Y$, Wang $K$, Zhang $X$, Zheng $Y$ (2014) An optimized Nash nonlinear grey Bernoulli model based on particle swarm optimization and its application in prediction for the incidence of Hepatitis B in Xinjiang, China. Computers in Biology and Medicine 49: 67-73.

14. Zhou H, Huang J, Yuan Y, Tang B (2014) Prediction of Water Consumption in Hospitals Based on a Modified Grey GM $(0,1 / \sin )$ Model of Oscillation Sequence: The Example of Wuhan City. Journal of Applied Mathematics.

15. Chen $\mathrm{Cl}$, Huang SJ (2013) The necessary and sufficient condition for $\mathrm{GM}(1,1)$ grey prediction model. Applied Mathematics and Computation 219: 6152-6162.

16. Chen $\mathrm{Cl}$, Chen HL, Chen SP (2008) Forecasting of foreign exchange rates of Taiwan's major trading partners by novel nonlinear Grey Bernoulli model $\operatorname{NGBM}(1,1)$. Communications in Nonlinear Science and Numerical Simulation 13: $1194-1204$.

17. Chang SC, Lai HC, Yu HC (2005) A variable P value rolling Grey forecasting model for Taiwan semiconductor industry production. Technological Forecasting and Social Change 72: 623-640.

18. Wen KL (2004) Grey Systems: Modeling and Prediction, Arizona: Yang's. 